Supplement of Clim. Past, 14, 2037-2052, 2018

https://doi.org/10.5194/cp-14-2037-2018-supplement

(C) Author(s) 2018. This work is distributed under

the Creative Commons Attribution 4.0 License.

(c) (i)

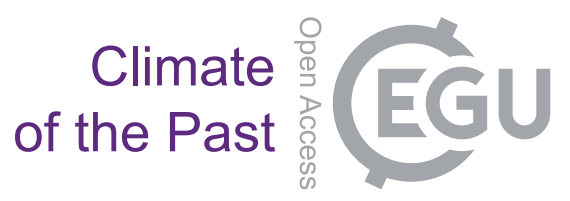

Supplement of

\title{
Understanding the Australian Monsoon change during the Last Glacial Maximum with a multi-model ensemble
}

Mi Yan et al.

Correspondence to: Jian Liu (jliu@njnu.edu.cn)

The copyright of individual parts of the supplement might differ from the CC BY 4.0 License. 


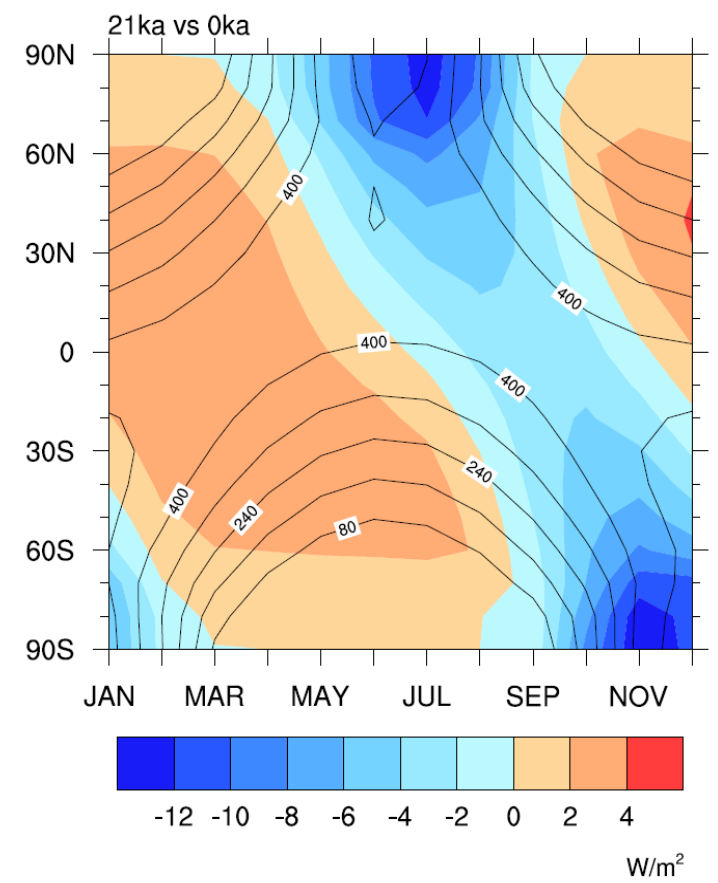

29 Figure S1 Change of the insolation during the LGM. The insolation during PI is plotted in 30 contours, and the difference between the LGM and the PI is color-shaded (units in $\mathrm{W} \mathrm{m}^{-2}$ ).

31 Reprint of Fig. 2 in Yan et al. (2016). 
33

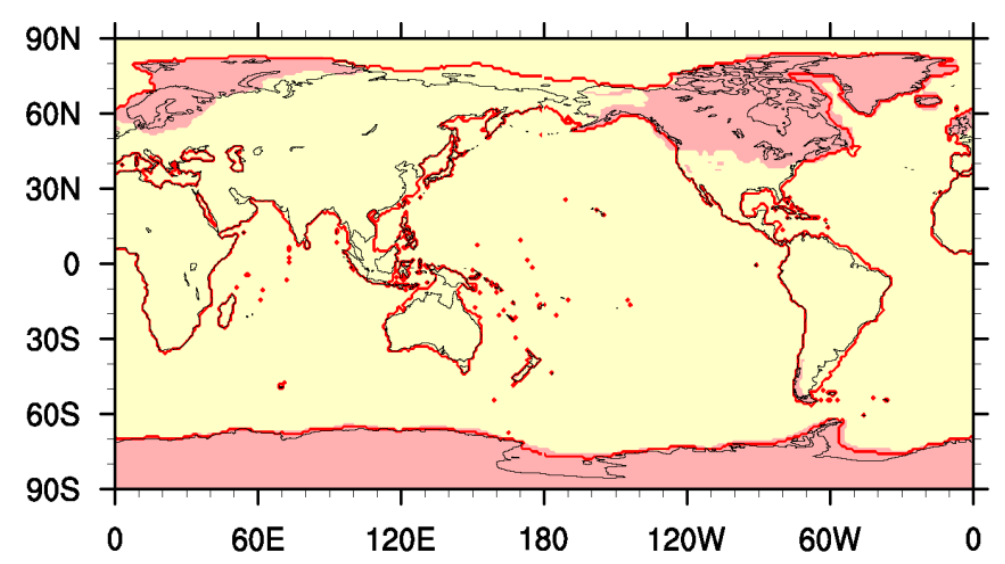

34

35 Figure S2 Distributions of the land-sea mask and land-ice during the LGM. The land-sea mask

36 during the LGM is in red contour. The land-sea mask during the PI is in black contour. The land

37 ice-sheet is color-shaded. Reprint of Fig. 1 in Yan et al. (2016).

38 


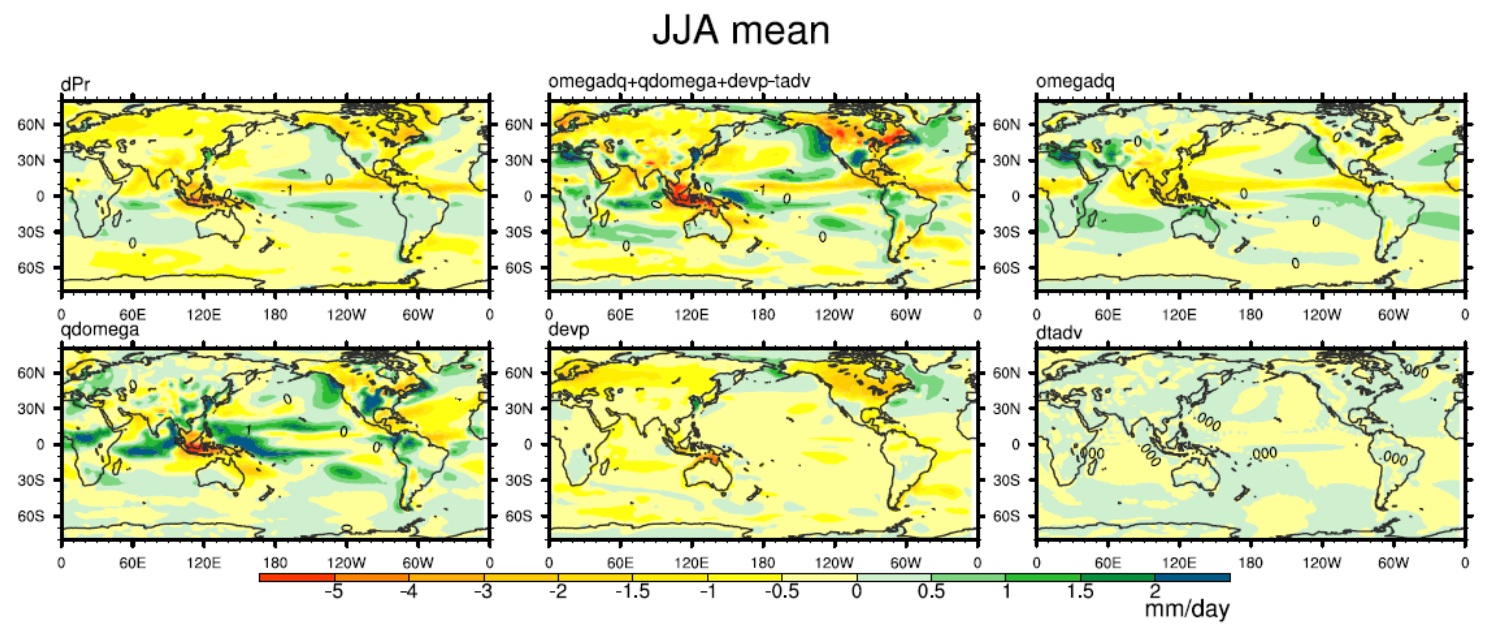

39

40 Figure S3 The JJA mean difference between LGME and piControl derived from 7MME. Shown

41 are precipitation (top left), sum of each term (top center), thermodynamic term (top right),

42 dynamic term (bottom left), surface evaporation (bottom center) and advection term (bottom

43 right).

44

45 
(a) JJA mean z850 with wind850

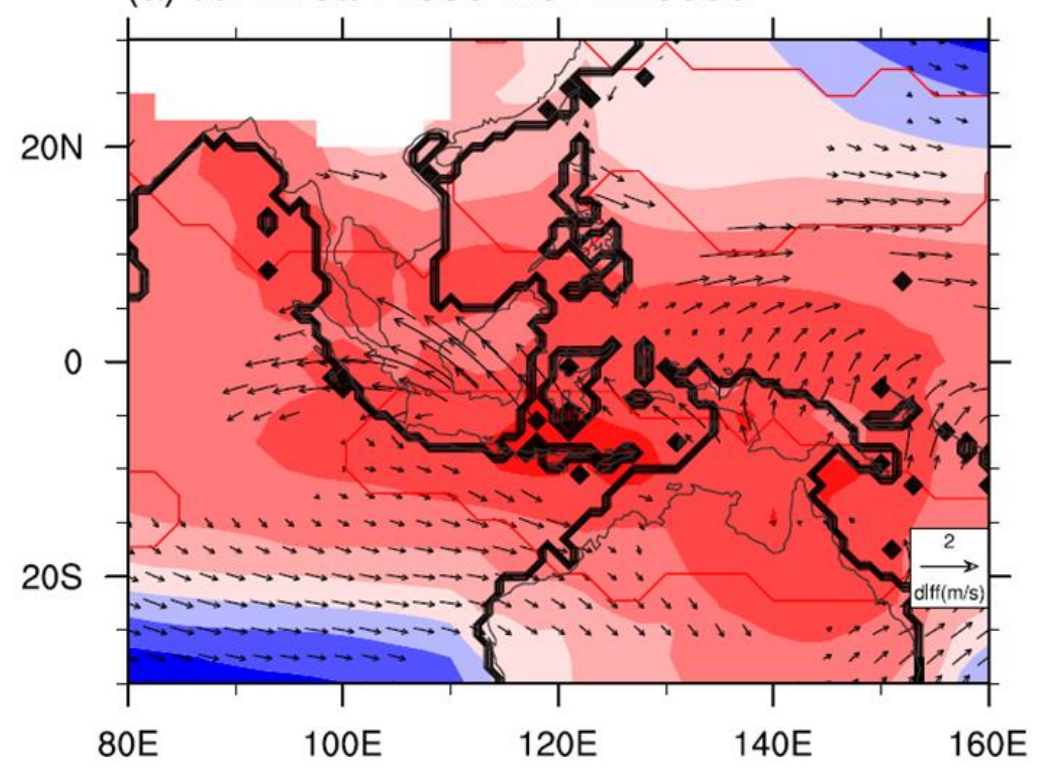

(b) ND mean z850 with wind850

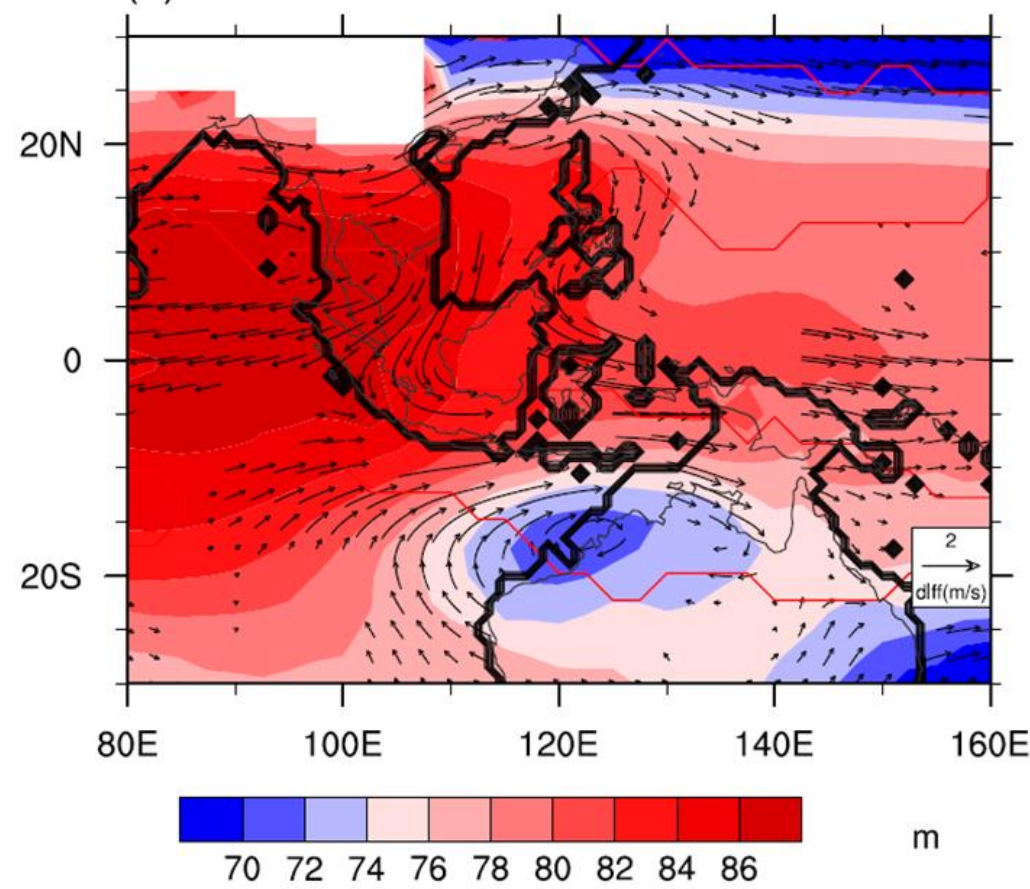

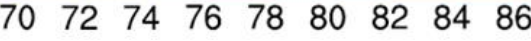

48 Figure S4 The (a) JJA mean, and (b) ND mean $850 \mathrm{hPa}$ geopotential height (shading) with 850

$49 \mathrm{hPa}$ wind (vector) difference between LGME and piControl. The red lines enclose the monsoon

50 domains. The thick black lines denote the coastal lines in LGME provided by CMIP5/PMIP3, and

51 the thin black lines denote the coastal lines in piControl. Only those areas where signal-to-noise

52 ratio exceeds one are plotted. 

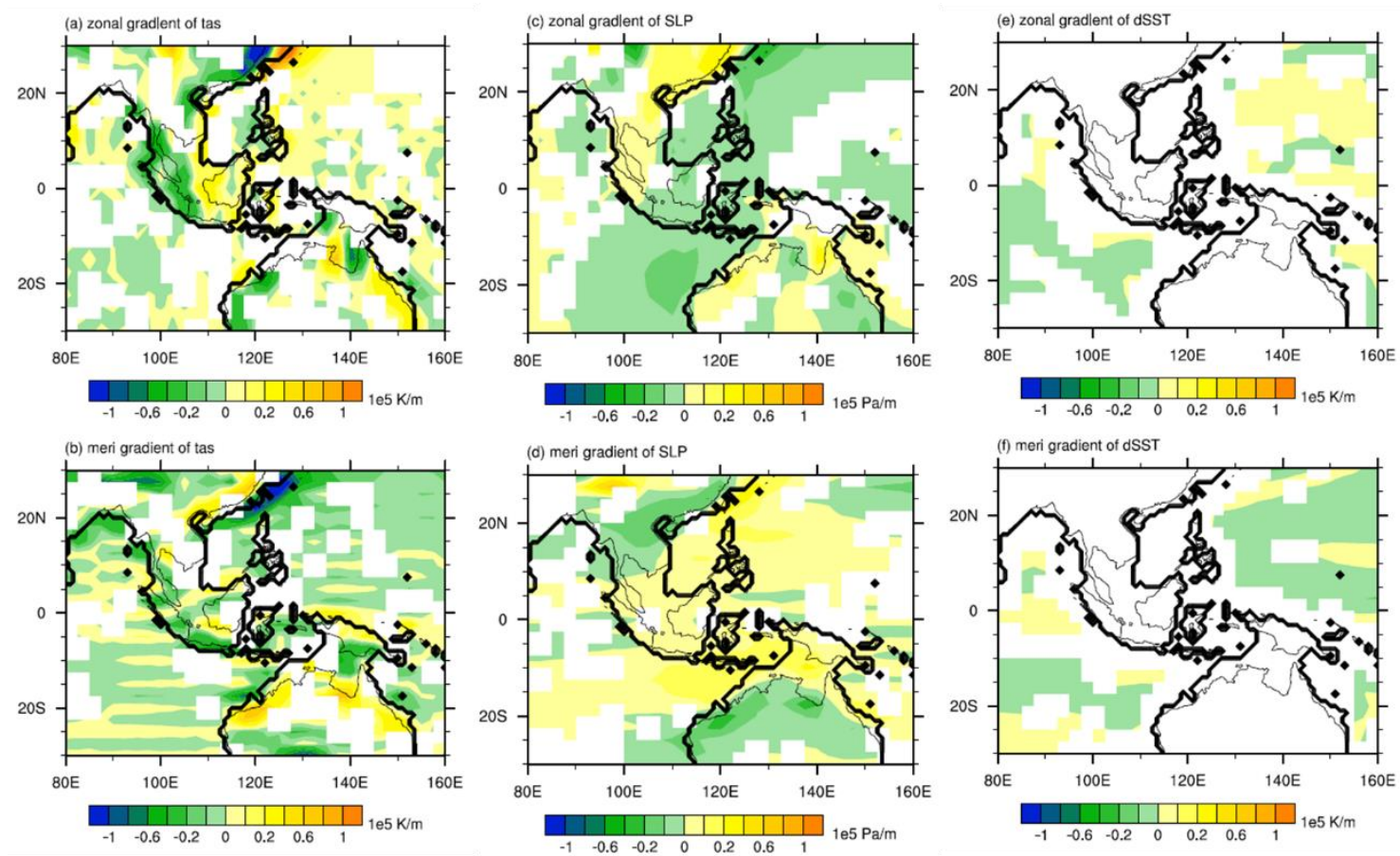

Figure S5 The ND mean zonal (top panels) and meridional (bottom panels) gradient difference

57 between LGME and piControl. (a)-(b) for surface air temperature anomaly, (c)-(d) for sea level

58 pressure anomaly, and (e)-(f) for sea surface temperature anomaly. The thick black lines denote

59 the coastal lines in LGME provided by CMIP5/PMIP3, and the thin black lines denote the coastal

60 lines in piControl. Only those areas where signal-to-noise ratio exceeds one are plotted. 
62

\section{ND mean}

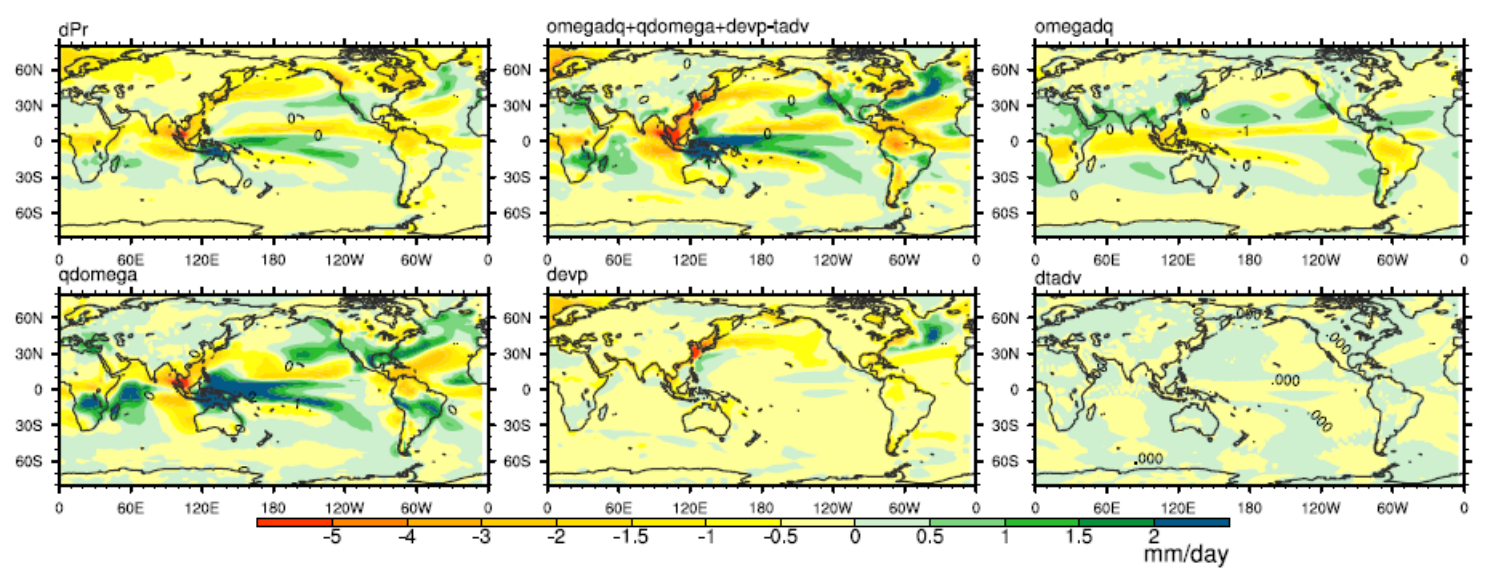

63

Figure S6 Same as Fig. S3, but for ND mean.

65 
66

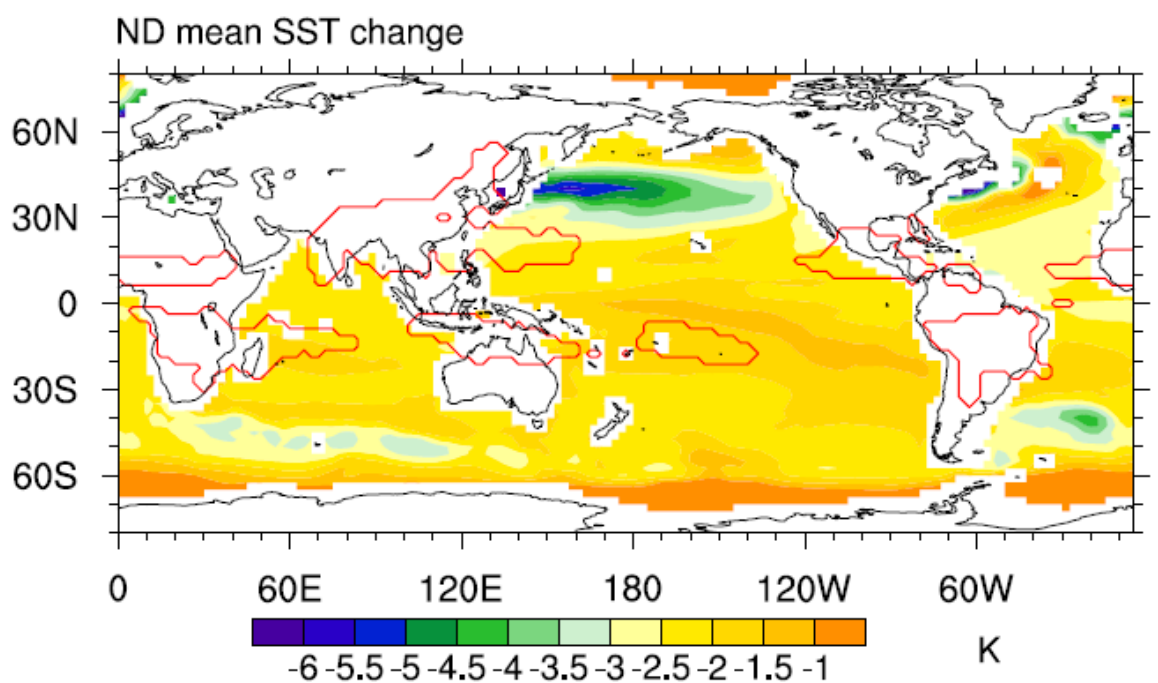

67 Figure S7 The ND mean SST difference between the LGME and piControl. The orange lines

69 enclose the monsoon domains. Only those areas where signal-to-noise ratio exceeds one are

70 plotted.

71 


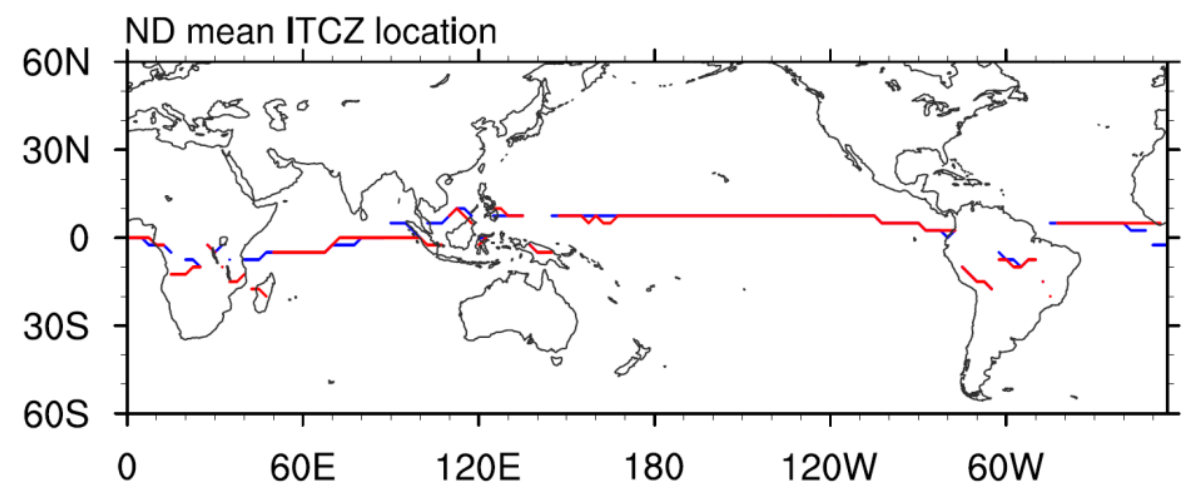

78 Figure S8 The 7MME ND mean ITCZ location defined by the meridional maximum

79 precipitation between $20^{\circ} \mathrm{S}$ and $20^{\circ} \mathrm{N}$. The red line indicates the position during the LGM and the 80 blue line indicates the position during the PI. 

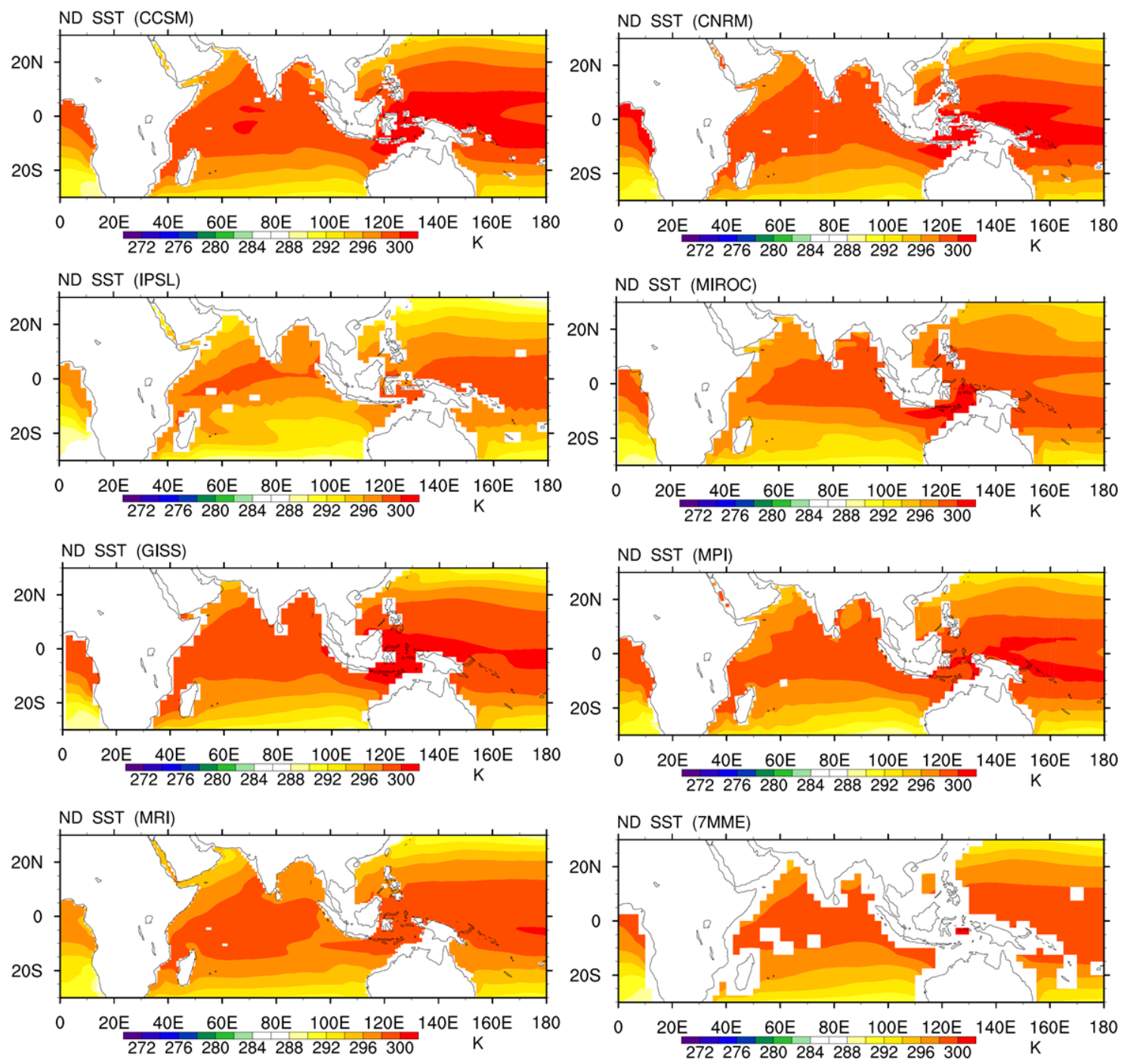

82

83 Figure S9 ND mean SST in LGME derived from each model and 7MME.

84 